\title{
Using the ASSIST Short Form for Evaluating an Information Technology Application: Validity and Reliability Issues
}

\author{
Carol A. Speth, Deana M. Namuth, and Donald J. Lee \\ University of Nebraska-Lincoln, College of Agriculture and \\ Natural Resources, Lincoln, Nebraska, USA
}

\author{
cspeth2@unl.edu; dnamuth1@unl.edu; dlee1@unl.edu
}

\begin{abstract}
In this study, the Approaches and Study Skills Inventory for Students (ASSIST) short form was used to gain insight about learning style characteristics that might influence students' use of an online library of plant science learning objects. This study provides evidence concerning the internal consistency reliability and construct validity of the Deep, Strategic and Surface scale scores when used to sort students' responses. Participants consisted of 446 resident university students (230 males, 216 females) in agricultural science courses with face-to-face instruction supplemented with web-based lessons. Cronbach's alphas for the three scales ranged from 0.65 to 0.75 . The data file was submitted to a maximum likelihood factor analysis with oblimin rotation. When three factors were extracted, all 18 items loaded on the expected factors. One example of an analysis based on ASSIST scale scores is presented to show the potential of this procedure for helping with the interpretation of student comments.
\end{abstract}

Keywords: learning styles, learning objects, approaches to studying, instructional technology, online instruction, genetics, science teaching, evaluation.

\section{Introduction}

The Library of Crop Technology is a collection of web-based learning objects developed initially at a large mid-western American university with help from other universities and funding agencies to provide peer-reviewed, unbiased science-based information about biotechnology and other plant science topics to students in either resident or distance courses, participants in extension or outreach activities, and members of the public. University instructors, community college teachers, adult educators, high school science and agriculture teachers, agronomists, seed company sales representatives, industry trainers, crop consultants, journalists, dieticians, and nutritionists have used it. It has now been expanded and renamed the Plant and Soil Sciences eLibrary (Namuth, Fritz, King, \& Boren, 2005).

Material published as part of this publication, either on-line or in print, is copyrighted by the Informing Science Institute. Permission to make digital or paper copy of part or all of these works for personal or classroom use is granted without fee provided that the copies are not made or distributed for profit or commercial advantage AND that copies 1) bear this notice in full and 2) give the full citation on the first page. It is permissible to abstract these works so long as credit is given. To copy in all other cases or to republish or to post on a server or to redistribute to lists requires specific permission and payment of a fee. Contact Publisher@InformingScience.org to request redistribution permission.
Formative evaluations of the lessons included a volunteer group of students interested in crop genetic engineering and students in two semesters of an introductory genetics course (Hain, 1999). Students were interviewed and asked open-ended questions about their learning strategies relative to six features of the lessons: objectives, text, images, animations, glossary and quizzes. 
As the database of lessons and topics grew, the developers' interest in self-reported strategies evolved into a research program including students at several universities who were using the learning objects library. This research program made it possible to assemble a larger and more heterogeneous sample and, as a side effect, get a better sense of the reliability and validity of the ASSIST scales. Those results are reported here.

\section{Validity and Reliability}

Two indicators of quality for any kind of mental measurement are validity and reliability. According to Allen and Yen $(1979$, p. 95), "A test has validity if it measures what it purports to measure," and "Validity can be assessed in several ways, depending on the test and its intended use." Richardson $(2004$, p. 353$)$ stated that, "Any research instrument should be validated from scratch in each new context in which it is used." According to the StatsDirect Limited (2006b) online dictionary of statistics terms, located at http://www.camcode.com/help/validity.htm, for laboratory experiments with tightly controlled conditions, it is easier to achieve high internal validity than for studies in difficult to control environments (like classrooms).

The other hallmark of quality in the measurement world, reliability, means that the test or questionnaire measures what it claims to measure consistently, either in terms of consistency over time, or that the items combined to produce scores have high enough positive inter-item correlations to produce meaningful scores. A coefficient of reliability can be calculated based on various formulas (Allen \& Yen, 1979, pp. 72-92). Lee Cronbach of Stanford University developed one commonly used formula for calculating the internal consistency of items on a scale, called Cronbach's alpha or $\alpha$. According to StatsDirect Limited (2006a), located at http://www.camcode.com/help/reliability.htm, by convention, an alpha of 0.80 is considered adequate for many purposes. But the adequacy of a coefficient of reliability depends on the type of scale and the purposes for which the scores are being used. One example, from outside the approaches to studying literature, comes from Schott and Bellin, (2001, p. 88) who were interested in questionnaires measuring self-concept, and who considered reliabilities of 0.69 to 0.77 acceptable.

Koohang (2004) reported development of a new instrument to facilitate evaluation of the usability of digital libraries. He addressed the issue of construct validity by doing a principal components factor analysis of the items, and found his items all addressed one trait. The internal consistency of his scale was 0.96 . This study describes a similar process, but the ASSIST had a longer history, with adaptations for new purposes and modifications to widen its theoretical base.

\section{Background: Development and Previous Use of the ASSIST and its Predecessors}

The 1960s and 1970s was a period of growth and change for higher education around the world. Increasing demand for higher education, and public and judicial concern with equalizing opportunities led administrators, government officials, and funding agencies to look for new ways to improve the quality of learning for students who might not have entered higher education in such numbers in previous decades. Equalizing educational opportunity means more than just allowing access to higher education courses, but also making course content accessible to students with different characteristics.

In England, beginning in 1968, a six-year study looked at the relationship of personality, motivation, and study methods to academic performance. A research team at the University of Lancaster found that study methods and relatively stable personality traits, like introversion and extroversion, were only weakly correlated to achievement (Entwistle \& Ramsden, 1983, p. 6). Gradually, that research team broadened their focus from predicting academic achievement to understanding 
students' experience and quality of learning. Some of their inspiration came from Biggs (1978), in Australia, who was looking at how the processes of learning influence the outcomes, and how both are affected by learner variables, such as motivation or strategy.

In 1976, a five-year study based at Lancaster University eventually included 3223 students at 66 universities and technical colleges in Britain. A contrast of Deep to Surface Approaches, based partly on interview research in Sweden by Marton and Säljö (1976a, 1976b) and their colleagues, Fransson (1977) and Svensson (1977), was written into the 64-item "Approaches to Studying Inventory" (ASI), along with a "Strategic Approach," identified by interviews of students who were intent on getting the best possible grade with efficient use of time and effort and careful attention to instructors' cues about assessment demands (Entwistle \& Ramsden, 1983). Students identified as using a Strategic Approach were motivated by a need to achieve, as opposed to a fear of failure. The term "approach" was chosen to convey a broader meaning than the term "processing" and indicate an interactive relationship between the learner and the learning environment (CanoGarcia \& Justicia-Justicia, 1994, p. 241.) As Table 1 indicates, the contrast of deep to surface approaches to learning or studying is most evident on the Surface Scale, where two items refer to the strategy of unrelated memorizing and two refer to the motivation of avoiding failure.

\section{Computerized Assessment of Learning Styles}

Insights from another study by Gordon Pask in England (1976a, 1976b) were incorporated into the ASI (Entwistle \& Ramsden, 1983, pp. 22-28, 35, 41, 75-76). The contrast of holist to serialist was not unique to Pask, but his method of investigation, using computer-based learning materials and science fiction content (to exclude prior learning as a relevant variable), was unusual. Pask might have been among the first to look at how the quality of learning from computer-based instruction materials is affected by differences in learning style. He suggested that learners might be predisposed toward either operation learning with an emphasis on procedure building, or comprehension learning with an emphasis on description building. According to Pask, operation learning includes careful use of evidence, while comprehension learning includes looking for a relationship among ideas.

Ford's (1985) study assessing 82 graduate students with Pask's computer programs and the ASI short form, found that even these advanced learners had a decided bias toward either operation learning or comprehension learning. Both Pask and Ford suggested that really effective learning requires both.

Entwistle and Ramsden (1983, p. 75-76) saw potential in Pask's ideas, but their students reacted with impatience to computer-based assessment. Computers at that time were not very userfriendly, and few students had computer skills yet. Pask's ideas were brought into the ASI by means of items on Relating Ideas ("I try to see how all the ideas fit together") and Use of Evidence ("I examine the details carefully"). Students who agree with both kinds of items are presumably more versatile. As Table 1 indicates, four items on the Deep Scale of the ASSIST trace their origins back to Pask's work on relating ideas and using evidence.

\section{Cognitive Psychology and Information Processing}

In the United States, the Inventory of Learning Processes (Schmeck, Ribich, \& Ramanaiah, 1977) was based on theories of cognitive psychology. Several studies have been reported in which the Approaches to Studying Inventory (ASI) was administered along with the Inventory of Learning Processes (ILP), using factor analyses to identify similarities and differences (Entwistle \& Waterston, 1988, in Scotland, Speth \& Brown, 1988, in the United States, and Cano-Garcia \& Justicia-Justicia, 1994, in Spain). 
Table 1

Scale Reliability Analysis of the 18 ASSIST Items

\begin{tabular}{cc} 
Item to & Scale alpha \\
scale total & if item \\
correlation & deleted \\
\hline
\end{tabular}

Deep Scale Cronbach's alpha $=0.65$

2. When I'm reading an article or book, I try to find out for myself exactly

$0.43 \quad 0.59$

what the author means. (Seeking meaning)

6. Regularly, I find myself thinking about ideas from lectures when I'm doing $\quad 0.40 \quad 0.60$

other things. (Interest in ideas)

10. When I'm working on a new topic, I try to see in my own mind how all the $\quad 0.46 \quad 0.57$

ideas fit together. (Relating ideas)

15. Ideas in course books or articles often set me off on long chains of thought $\quad 0.36 \quad 0.61$

of my own. (Relating ideas)

12. Often I find myself questioning things I hear in lectures or read in books. $\quad 0.30 \quad 0.64$

(Use of evidence)

17. When I read, I examine the details carefully to see how they fit in with $\quad 0.33 \quad 0.63$

what's being said. (Use of evidence)

Strategic Scale Cronbach's alpha $=0.75$

3. I organize my study time carefully to make the best use of it. (Time

$0.52 \quad 0.70$

management)

7. I'm pretty good at getting down to schoolwork whenever I need to. $\quad 0.57 \quad 0.69$

(Time management)

5. I look carefully at instructor's comments to see how to get higher grades next $\quad \begin{array}{lll}0.42 & 0.73\end{array}$

time. (Alert to assessment)

13. I manage to find conditions for studying which allow me to get on with $\quad 0.55 \quad 0.70$

my work easily. (Organized studying)

9. I put a lot of effort into studying because I'm determined to do well. $\quad 0.65 \quad 0.67$

(Achieving)

11. I don't find it at all difficult to motivate myself. (Achieving)

$0.24 \quad 0.77$

Surface Scale Cronbach's alpha $=0.70$

1. Often I find myself wondering if the work I am doing here is really worthwhile.

$0.45 \quad 0.65$

(Lack purpose)

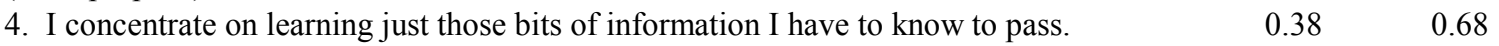

(Syllabus bound)

8. Much of what I'm studying makes little sense. It's like unrelated bits and pieces. $\quad 0.46 \quad 0.65$

(Unrelated memorizing)

18. I often have trouble in making sense of the things I have to remember. $\quad 0.46 \quad 0.65$

(Unrelated memorizing)

14. Often I feel I'm drowning in the sheer amount of material we have to deal with. $\quad 0.37 \quad 0.68$

(Fear of failure)

16. I often worry about whether I'll ever be able to cope with the school work

properly. (Fear of failure)

Rohwer (1984) invited educational psychologists to pay more attention to autonomous learning (or studying), rather than putting so much emphasis on instruction. A number of research studies were suggesting that even learning from lectures required more self-direction than had been previously assumed. American researchers in the field of autonomous studying identified two broad categories of study activities: Cognitive Transformation and Self-Management (Rohwer, 1984; 
Strage, Christopoulos, Curley, Jensen, \& Thomas, 1987; Thomas \& Rohwer, 1986). Along with some items based on that autonomous studying research, Speth and Brown administered the ASI and ILP to 383 students in teacher education classes at an American university. Their factor analysis (of subscales rather than items) identified four common emphases of questionnaires from three different research perspectives: (1) Time- and effort-intensive organized study methods; (2) An intention to understand, personalize and integrate the information being learned; (3) Strategic or context sensitive study behavior; and (4) An intention to reproduce information, unaware of external cues and without personal involvement (Speth \& Brown, 1988, p. 255). As Table 1 indicates, the influence of this field of research is most obvious in the Strategic Scale items on the ASSIST.

\section{Approaches to Studying Tried in Different Countries and Settings}

Besides comparing questionnaires from different research perspectives, another line of research has explored the portability of the ASI scales (and the psychological constructs they represent) to different cultural contexts. Richardson (1994, pp. 78-79) asserted that the factor structure of the ASI scales did not hold up well enough, especially in the United States. Richardson also suggested dropping the Strategic Approach because it is too culture or context-specific.

Watkins, Hattie and Astilla (1986) administered a 30-item ASI short form to 212 male and 213 female Filipino university students who were instructed in English. They used confirmatory factor analysis and reported a good fit between the expected factor structure and their data, which demonstrated the validity of that short form in a third world setting. Watkins and Regmi (1996) administered the ASI to 302 first-year students in Nepal and found support for the cross-cultural validity of the scales and the constructs they represent. Based on ASI results, through the years, Watkins has made comparisons between learners in Nigeria, Australia, Hong Kong, Nepal and the Philippines (Watkins \& Akande, 1994).

Another research and development effort by scholars around the world has been to test and improve the ASI items and scales. In due course, the Revised ASI or RASI appeared (Entwistle \& Tait, 1994). Duff (1997) administered a 30-item short form of the RASI to 356 undergraduate business students at the University of Paisley in Scotland. Duff reported reliability coefficients for the scales of the RASI between 0.80 and 0.82. Sadler-Smith and Tsang (1998) administered a 38item version of the RASI to 225 UK and 183 Hong Kong students. For the Hong Kong students, they reported reliability coefficients (Cronbach's $\alpha$ ) of 0.67 for the Deep, 0.73 for the Strategic and 0.59 for the Surface Scales, compared to $0.79,0.82$ and 0.79 for the British sample.

At the University of Edinburgh, Scotland, between 1995-1998, the RASI was revised again to strengthen its psychometric characteristics (Duff, 1997). Tait and Entwistle (1996) reported scale reliability coefficients from 0.77 to 0.83 . They described work on a new 44 -item version to be called the ASSIST. Entwistle, Tait and McCune (2000) used the ASSIST to gather data in South Africa and Scotland. Compared to the ASI, the Strategic Scale on the ASSIST was "broadened to include an aspect of metacognition and self-regulation," in other words, trying to monitor the effectiveness of one's own studying (Centre for Research on Learning and Instruction, 1997).

\section{Objectives}

This study builds upon the research cited above by contributing evidence concerning the internal consistency of the Deep, Strategic and Surface scales of the ASSIST. By collecting data from agricultural science students in the United States, it supplies cross-cultural evidence. This data was collected as part of a larger research and evaluation program related to the Internet-based Library 
of Crop Technology, (now called the Plant and Soil Sciences eLibrary), a tool for learning outside of class (studying).

Specific objectives for this study include finding out if the items emerge on factors as expected, and if the reliability coefficients for the scales are high enough to support using scale scores to identify groups of students with similar characteristics. Finally, as a test of the validity of the scales and scoring procedure, student comments are sorted into three groups to see if they are easier to interpret. Without using the ASSIST, Jewels and Ford (2004) tried to classify students' comments to help them evaluate whether a case study method of teaching an Information Technology Project Management course contributed to students' learning and understanding. Jewels and Ford found their procedure was "too weak and subject to extraneous influences."

\section{Sample}

Since all the research participants had to be enrolled in agricultural science courses that were using lessons from the Library on Crop Technology, and all had to formally agree to participate in the study, this would be considered a sample of convenience rather than a random sample. Combining ASSIST data from six semesters of the introductory genetics course and students at other universities using the same lessons brought the number of cases up to 446 (230 males, 216 females) students, enough to do a factor analysis. This sample included nine first year, 105 second year, 146 third year, 158 fourth year, and 28 graduate students. Their major fields of study included 61 Agronomy, 88 Animal Sciences; 82 Biology and/or Chemistry; 62 Diversified Agriculture or Mechanized Systems; 20 Range Science, and 68 Veterinary Science. All these students formally agreed to participate in the study according to procedures for the protection of human subjects required by this university's Institutional Review Board.

\section{Method}

The ASSIST was obtained from the authors and checked for wording and spelling that might be unfamiliar or misleading to American students. The same list of items and scoring key for the ASSIST is now available online (Centre for Research on Learning and Instruction, University of Edinburgh, 1997, located at http://www.ed.ac.uk/etl/questionnaires/ASSIST.pdf.). The word "tutor" was changed to "instructor," and "marks" to "grades." No further translation from British to American English seemed necessary. Students were asked to complete the 18-item short form, which has six items on each of three scales: Deep, Strategic and Surface. On each item, students chose one of the following, 5=Strongly Agree, 4=Agree, 3=Neutral or Undecided, 2=Disagree, or $1=$ Strongly Disagree. Students were encouraged to avoid using the "Neutral or Undecided" response if possible.

An online form of the ASSIST was created in 2002. When students hit the "Submit" button, they were prompted to answer any questions they might have skipped. Then they were shown a list of their responses and a total of their Deep, Strategic and Surface scores, with no interpretation offered unless they asked for it. (Only one student out of 446 asked for an interpretation.) The students' answers were combined into an Excel data file. This data file was imported into the Statistical Package for the Social Sciences (SPSS) 12.0.1 for further analysis.

\section{Results}

Reliability coefficients (Cronbach's $\alpha$ ) for the three scales were 0.65 for the Deep, 0.70 for the Strategic, and 0.75 for the Surface Scale. These coefficients are within the range (from $\alpha=0.59$ to $\alpha=0.83$ ) found by research studies in other countries using earlier and longer versions of the Approaches to Studying Inventory. Table 1 lists the items and shows their correlations to the scale scores. On the Strategic Scale, Item 11 had a lower correlation to the total, which hurt the 
reliability of that scale. If more students were versatile learners (Ford, 1985), the reliability of the Deep Scale might have been higher, but many students have a strong preference for either comprehension learning (items 10 and 15) or operation learning (items 12 and 17). The two Operation Learning items had lower correlations to scale totals than the other four items on the Deep Scale. Several authors have found that Operation Learning (attention to detail) is related more to Strategic Approach (Cano-Garcia \& Justicia-Justicia, 1994, p. 252; Speth \& Brown, 1988, p. 251), but that did not happen in this study.

Table 2 shows the results of a factor analysis of these 18 items. Factor analysis is used to identify groups of items that are highly correlated, either negatively or positively. Ideally, there would be low or negative correlations between pairs of factors, which would indicate that most students who agree with the items on one scale disagree with items on another. Low or negative correlations highlight the differences between factors, indicating that the items on each factor measure different constructs. Correlations between scales are shown at the bottom of Table 2. The 0.27 correlation between the deep and strategic scales is similar to results obtained in other studies.

Duff (1997) recommended using principal axis factor analysis because it makes no assumption of independence or orthogonality. However, Entwistle, Tait and McCune (2000) reported results from a maximum likelihood factor analysis, and that kind of analysis will be reported here. The next two decisions are the number of factors to be extracted and which kind of rotation of the factor matrix is most appropriate. Duff (1997) said that oblique rotation is necessary when scales are conceptually related and likely to correlate with each other. For that reason, he chose oblimin rotation, and that type of rotation will be reported here. (For a long discussion of the potential contributions of different kinds of factor analysis and rotation, see Cano-Garcia \& Justicia-Justicia, 1994, p. 252.)

Table 2 shows the results of a maximum likelihood factor analysis limited to three factors. There was a clear match between the three factors and the ASSIST scales. For the "Alert to Assessment" item, the highest loading was on the Deep Factor, but there was also a 0.31 loading on the Strategic Factor. It is highly adaptive for students who prefer to take a Deep Approach to also be alert to assessment demands.

\section{Description of Groups Based on ASSIST Scale Scores}

It was essential to verify that three approach scale scores for individuals do indeed convey meaningful information, even though no decisions about individual students are based on the scores. The original plan was to assign individuals to groups based on their highest raw score of the Deep, Strategic and Surface Scales. But several students had equal raw scores on two of the scales. In educational measurement, it is common to use one of several kinds of "transformed" scores, including percentiles and standard scores, rather than raw scores, because they tell more about an individual's score in relation to the group. Standard or "Z" scores, which convey information about the distribution of scores, were calculated for each student on each of the three scales: Deep, Strategic and Surface. The " $Z$ " score for an individual student is (total score for each scale minus the mean of all scores on that same scale) divided by the standard deviation for all the scores on that scale (Allen \& Yen, 1979, pp. 161-163).

Students were assigned to one of three groups to see if the proportions were similar to what was obtained in smaller studies. In a pilot study, the proportion of students whose highest $Z$ score was on the Deep Scale was nearly equal to the proportion whose highest $Z$ score was on the Strategic Scale. Out of this larger sample of 446 students, 133 were assigned to the Deep, 125 to the Strategic, and 188 students to the Surface Group. These proportions have been fairly consistent across several semesters of data collected from this class. 


\section{Table 2}

\section{Three-Factor Pattern Matrix for the 18 ASSIST Items}

$$
(\mathrm{N}=446,47 \% \text { variance })
$$

Loadings greater than 0.25

\begin{tabular}{|c|c|c|c|c|}
\hline \multirow[b]{2}{*}{ Item Number } & & \multicolumn{3}{|c|}{ Factor } \\
\hline & & I & II & III \\
\hline & Deep Scale & & & \\
\hline 2 & Seeking Meaning & 0.46 & & \\
\hline 6 & Interest in Ideas & 0.50 & & \\
\hline 10 & Relating Ideas & 0.66 & & \\
\hline 15 & Relating Ideas & 0.43 & & \\
\hline 12 & Using Evidence & 0.28 & & \\
\hline 17 & Using Evidence & 0.32 & & \\
\hline & Strategic Scale & & & \\
\hline 3 & Time Management & & & 0.64 \\
\hline 7 & Time Management & & & 0.69 \\
\hline 5 & Alert to Assessment & 0.60 & & 0.31 \\
\hline 9 & Achieving & & & 0.63 \\
\hline 11 & Achieving & & & 0.35 \\
\hline 13 & Organized Studying & & & 0.53 \\
\hline & Surface Scale & & & \\
\hline 1 & Lack Purpose & & 0.38 & \\
\hline 4 & Syllabus Bound & & 0.30 & \\
\hline 8 & Unrelated Memorizing & & 0.35 & \\
\hline 18 & Unrelated Memorizing & & 0.56 & \\
\hline 14 & Fear of Failure & & 0.68 & \\
\hline 16 & Fear of Failure & & 0.62 & \\
\hline
\end{tabular}

\begin{tabular}{lrrr} 
& \multicolumn{4}{c}{ Correlations between factors } \\
& I & \multicolumn{1}{c}{ II } & \multicolumn{1}{c}{ III } \\
Factor I (Deep) & 1.00 & -0.06 & 0.27 \\
Factor II (Surface) & -0.06 & 1.00 & -0.16 \\
Factor III (Strategic) & 0.27 & -0.16 & 1.00
\end{tabular}

Extraction Method: Maximum Likelihood

Rotation Method: Oblimin with Kaiser Normalization

Rotation converged in 22 iterations 


\section{Application}

This sample of 446 students all took the ASSIST, but there was no single outcome variable for all of them. Comments from the Internet lesson evaluation forms were available for 116 who were enrolled in one genetics course. Sorting these comments by approach provides additional evidence of validity of the Deep, Strategic and Surface constructs and the scales used to measure them. Students whose highest $Z$ score was on the Deep Scale made comments about seeking understanding, searching for relationships among ideas, or preferring to learn on their own. A few felt they didn't really need the Internet lessons but conceded they were useful for helping them understand. One, whose assignment to the Deep Group was somewhat arbitrary as his score on the Deep Scale was not much more than his score on the Surface Scale, said, "Some of the questions seem unrelated to the material," indicating that this student was at least looking for relationships among ideas, one of the defining characteristics of Deep Approach. One or two students who were sorted into this group made comments that were not especially characteristic of Deep Approach, such as, "I liked everything. There was nothing wrong." Others wrote:

- They helped in understanding some topics.

- Some actually helped me understand what was discussed in class.

- They seemed like busy work to me.

- Before the test, I would make an outline of the objectives.

- I learn best on my own. Some of the wording was confusing.

- You should take them before the lecture to get the most benefit.

Students sorted into the Strategic Group often commented on the amount of time required and whether it was time well spent in terms of achievement.

- They should be worth more of our grade.

- I liked the detail, especially the animations. But access could be easier.

- The quizzes were time consuming. It took a lot of time to pass.

- I liked being able to go back and review the quizzes later.

- They were an easy grade. On the other hand, they took up time.

- I liked the animations. I learned a lot from them.

- Many questions are very similar. I did not like this.

Of the three groups, students whose highest $\mathrm{Z}$ score was on the Surface Scale showed the most appreciation of the lessons for making the content more accessible to them. This was a larger group of students with a wider range of comments. Several mentioned "repetition," which they considered a good thing, in the sense of reinforcing what they had learned in lectures and labs.

- They could be done anywhere, any time, even after midnight at work.

- They were a chance to learn at your own pace.

- I liked being able to do them at my own speed and time.

- The practice questions were similar to tests. They helped me review.

- I liked the visual aspect, and the quizzes were a great learning tool. 
- They made me read more thoroughly to get answers.

- They were a great way to study for exams. The repetition was helpful.

- You could go through them as many times as you needed.

- Time was hard to find, but it was worth it.

- I didn't like when they included content not in the text.

- They made me read more thoroughly to get the answers.

- Great way to study for exams. Provided an overview. I liked the repetition.

- They were a very effective study guide, but I got burned out on genetics.

\section{Conclusions and Related Studies}

Students bring their own objectives, motivations or intentions as well as levels of ability and commitment to a learning task. Students are complex creatures and no measure of learning styles or individual differences is perfect. But the ASSIST short form seems promising as an evaluation tool. This factor analysis supported the scoring procedure that Speth, Lee and Hain (2006) used.

Being able to sort students' comments into groups showed how learners with similar needs, intentions, and motivations made the Internet lessons work for them, and made it possible to say something besides, "Some liked it and some didn't." The categorized lists of comments provide additional evidence that the Deep, Strategic and Surface scale items measure what they purport to measure.

Another line of research inquiry has been to compare the groups in terms of how many times and for how long students accessed various lesson features. That study, which includes performance variables, may be reported separately. That study will address the issue raised by Jewels and Ford (2004) of relationships between approach and performance.

Several of the students quoted above suggested they were monitoring their own learning or cognitions, and a later study may include the Cognitive Monitoring items on the longer form of the ASSIST, which could be interpreted in the light of research on learning processes and autonomous studying.

\section{References}

Allen, M. J., \& Yen, W. M. (1979). Introduction to measurement theory. Monterey, CA: Brooks/Cole.

Biggs, J. B. (1978). Individual and group differences in study processes. British Journal of Educational Psychology, 48, 266-279.

Cano-Garcia, F., \& Justicia-Justicia, F. (1994). Learning strategies, styles and approaches: An analysis of their interrelationships. Higher Education, 27, 239-260.

Centre for Research on Learning and Instruction, University of Edinburgh. (1997). Scoring key for the approaches and study skills inventory for students. Retrieved April 7, 2006 from Enhancing TeachingLearning Environments in Undergraduate Courses Project Web site http://www.ed.ac.uk/etl/questionnaires/ASSIST.pdf

Duff, A. (1997). A note on the reliability and validity of a 30-item version of Entwistle \& Tait's revised approaches to studying inventory. British Journal of Educational Psychology, 67, 529-539.

Entwistle, N. J. \& Ramsden, P. (1983). Understanding student learning. London: Croom Helm.

Entwistle, N. J., \& Tait, H. (1994). The revised approaches to studying inventory. Edinburgh: Centre for Research on Learning and Instruction, University of Edinburgh. 
Entwistle, N. J., Tait, H., \& McCune, V. (2000). Patterns of response to an approache to studying inventory across contrasting groups and contexts. European Journal of the Psychology of Education, 15, 33-48.

Entwistle, N. J., \& Waterston, S. (1988). Approaches to studying and levels of processing in university students. British Journal of Educational Psychology, 58, 258-265.

Ford, N. (1985). Learning styles and strategies of postgraduate students. British Journal of Educational Psychology, 16, 65-77.

Fransson, A. (1977). On qualitative differences in learning: IV. Effects of intrinsic motivation and extrinsic test anxiety on process and outcome. British Journal of Educational Psychology, 47, 244-257.

Hain, P.M. (1999). Designing and evaluating Internet based lessons to teach crop genetic engineering. Unpublished master's thesis, University of Nebraska, Lincoln, Nebraska.

Jewels, T. \& Ford, M. (2004). A single case study approach to teaching: Effects on learning and understanding. Issues in Informing Science and Information Technology, 1, 359-372. Retrieved from http://articles.iisit.org/058jewel.pdf

Koolang, A. (2004). Development and validation of an instrument for assessing users' views about the usability of digital libraries. Issues in Informing Science and Information Technology, 1, 55-63. Retrieved from http://articles.iisit.org/018kooha.pdf

Marton, F., \& Säljö, R. (1976a). On qualitative differences in learning: I. Outcome and process. Symposium: Learning processes and strategies. British Journal of Educational Psychology, 46, 4-11.

Marton, F., \& Säljö, R. (1976b). On qualitative differences in learning: II. Outcome as a function of the learner's conception of the task. Symposium: Learning processes and strategies. British Journal of Educational Psychology, 46, 115-127.

Namuth, D., Fritz, S., King, J. \& Boren, A. (2005). Principles of sustainable learning object libraries. Interdisciplinary Journal of Knowledge and Learning Objects, 1, 181-196. Retrieved from http://ijklo.org/Volume1/v1p181-196Namuth.pdf

Pask, G. (1976a). Conversational techniques and the study and practice of education. British Journal of Educational Psychology, 46, 12-25.

Pask, G. (1976b). Styles and strategies of learning. British Journal of Educational Psychology, 46, 128148.

Richardson, J. T. E. (1994). Using questionnaires to evaluate student learning: Some health warnings. In: G. Gibbs (Ed.), Improving student learning: Theory and practice (pp. 73-88). Oxford: Oxford Brookes University, The Oxford Center for Staff Development.

Richardson, J. T. E. (2004). Methodological issues in questionnaire-based research on student learning in higher education. Educational Psychology Review, 16, 347-358.

Rohwer, W. D., Jr. (1984). An invitation to an educational psychology of studying. Educational Psychologist, 19, 1-4.

Sadler-Smith, E., \& Tsang, F. (1998). A comparative study of approaches to studying in Hong Kong and the United Kingdom. British Journal of Educational Psychology, 68, 81-93.

Schmeck, R. R., Ribich, F., \& Ramanaiah, N. (1977). Development of a self-report inventory for assessing individual differences in 1earning processes. Applied Psychological Measurement, 1, 413-431.

Schott, G. R., \& Bellin, W. (2001). An examination of the validity of positive and negative items on a single scale instrument. Evaluation and Research in Education, 15, 84-94.

Speth, C., \& Brown, R. (1988). Study approaches, process and strategies: Are three perspectives better than one? British Journal of Educational Psychology, 58, 247-257.

Speth, C. A., Lee, D. J. \& Hain, P. M. (2006). Prioritizing improvements in Internet instruction based on learning styles and strategies. Journal of Natural Resources and Life Sciences Education, 35, 34-41. 
StatsDirect Limited. (2006a). Reliability. Retrieved April 7, 2006 from http://www.camcode.com/help/reliability.htm

StatsDirect Limited. (2006b). Validity. Retrieved April 7, 2006 from http://www.camcode.com/help/validity.htm

Strage, A., Christopoulos, J. P., Curley, R., Jensen, J., \& Thomas, J. W. (1987, April). Course-specific differences in academic studying: Study activities, study time, achievement, and student differences. Paper presented at the Annual Meeting of the American Educational Research Association, Washington, D.C.

Svensson, L. (1977). On qualitative differences in learning: III. Study skill and learning. British Journal of Educational Psychology, 47, 233-243. (Symposium: Learning processes and strategies).

Tait, H. \& Entwistle, N.J. (1996). Identifying students at risk through ineffective study strategies. Higher Education, 31, 97-116.

Thomas, J. W., \& Rohwer, W. D., Jr. (1986). Academic studying: The role of study strategies. Educational Psychologist, 21, 19-41.

Watkins, D., \& Akande, A. (1994). Approaches to learning of Nigerian secondary school children. International Journal of Psychology, 29, 165-182.

Watkins, D., Hattie, J., \& Astilla, E. (1986). Approaches to studying by Filipino Students: A longitudinal investigation. British Journal of Educational Psychology, 56, 357-362.

Watkins, D., \& Regmi, M. (1996). Toward the cross-cultural validation of a western model of student approaches to learning. Journal of Cross-Cultural Psychology, 27, 547-560.

\section{Biographies}

Correspondence regarding this article should be addressed to Carol A. Speth, The University of Nebraska-Lincoln, Department of Agronomy and Horticulture, 279 Plant Science Building, Lincoln, NE 68583-0915; e-mail: cspeth2@unl.edu.

All three authors work for the Agronomy and Horticulture Department at the University of Nebraska-Lincoln. They were part of a team (representing several universities and departments) that won the 2004 ADEC National Excellence in Distance Education Award for the Library of Crop Technology, which is now part of the Plant and Soil eLibrary. This open source database has been tested with thousands of learners and is used by teachers and journalists internationally. Lessons and animations cover topics in crop technology, genetics, and weed science, nutrition and food safety. Some lessons are available in Spanish. Funding has been provided by grants from the American Distance Education Consortium (ADEC), the United States Department of Agriculture (USDA), and the University of Nebraska, with industry support.

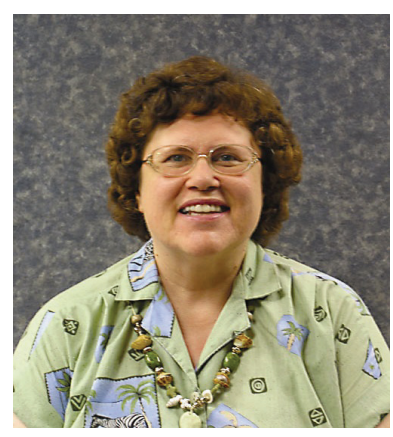

Carol Speth is an educational psychologist who does research on individual differences in student learning, with particular emphasis on learning from technology. While at the University of Edinburgh, she helped develop software to identify and help students at risk because of poor study skills, part of a Teaching and Learning Technology Project. While at the University of Kansas, she managed research and evaluation for the five-state Midlands Consortium Star Schools Project that providing secondary level instruction by satellite. 


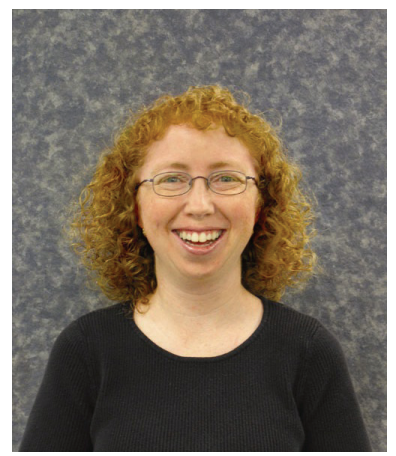

Deana Namuth, Distance Education Director, also teaches Introduction to Genetics. She directed the development, delivery and assessment of distance delivered modules, including workshops, satellite, Web-based and CD-ROM media types. These modules are available for noncredit, continuing education credit and academic credit learners. Her research includes looking at effective teaching methods for distance education programs and international collaborations.

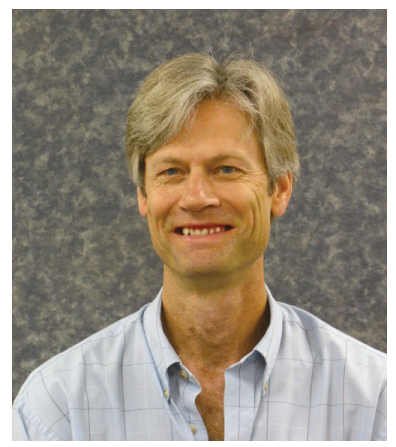

Donald Lee, Professor of Agronomy and Horticulture, is a plant geneticist. He teaches plant science to first-year students, and has taught Introduction to Genetics, Crop Genetics, and Crop Genetic Engineering. He has won grants for web site development in crop genetics and an American Distance Education Consortium (ADEC) grant for an open web site for lesson modules in crop science. He provides extension training on such topics as transgenic crop development and plant breeding. 